\title{
The human side in Structural Chemistry-a survey of 30 years
}

\author{
Balazs Hargittai ${ }^{1} \cdot$ Istvan Hargittai ${ }^{2}$ (D)
}

Received: 10 September 2020 / Accepted: 16 September 2020 / Published online: 7 October 2020

(C) The Author(s) 2020

\begin{abstract}
The journal Structural Chemistry has published reports of original research and reviews of research areas in all field of structural chemistry, creating and disseminating new knowledge, uncovering variations and regularities in structural information, and fostering discussions among scientists. In addition, from time to time, it communicates papers concerned with the history of the science of structures, obituaries of structural chemists, and reviews of books related to structural chemistry. These contributions that could be covered by the term of "the human side" are surveyed in this paper using the occasion of celebrating the 30year anniversary of launching this periodical.
\end{abstract}

Keywords Science history $\cdot$ Obituaries $\cdot$ Book reviews $\cdot$ Structural chemists $\cdot$ Human values

The contributions that could be assigned to refer to the human side of structural chemistry fall into three groups. One is science history [1-37] another is the obituaries of structural chemists [38-51], and the third group is the reviews of books relevant to structural chemistry [52-78]. The papers are listed chronologically within these three groups among the References. However, our survey below presents the material loosely according to scientific topics.

Herbert A. Hauptman (1917-2011) and Jerome Karle (1918-2013) were the champions of the direct methods in $\mathrm{X}$-ray crystallography. Hauptman gave a panoramic view of the development of X-ray crystallography from the very beginning [1]. Much of structural chemistry has been shaped by this technique, demonstrating also how much it means in a scientific field when new instrumentation and techniques become available. Hauptman emphasized, though, the limitations of the technique in both the size of the molecule and the accuracy of structural information achievable in determining crystal and molecular structures. The limitations stem

Istvan Hargittai

stuceditor@gmail.com

Balazs Hargittai

BHargittai@francis.edu

1 Department of Chemistry, Saint Francis University, 117 Evergreen Drive, Loretto, PA 15940, USA

2 Department of Inorganic and Analytical Chemistry, Budapest University of Technology and Economics, 4 Szent Gellert ter, Budapest 1111, Hungary primarily from the so-called phase problem. For a long time, the phase problem was considered unsolvable until, that is, Hauptman and Karle, and some others, worked out the mathematical tools leading to the direct methods. In their discovery that brought them the Nobel Prize in Chemistry in 1985, Hauptman and Karle relied, among other experiences, on the practice of the gas electron diffraction technique [79].

Isabella Karle (1921-2017) and Jerome Karle were among those who contributed a great deal to bringing up the level of accuracy of determining the structure of free (i.e., gaseous) molecules by electron diffraction in the late 1940s and early 1950s [79]. For certain peculiarities of handling the experimental data and extracting structural information from them, the so-called non-negativity principle was observed. This was connected to the way the contribution of the atomic scattering to the intensity distribution was eliminated in order to arrive at the intensity contribution originating from the interatomic interference. The application of the non-negativity principle was so fruitful that Hauptman and Karle wondered whether a similar criterion might be of use in the application of other techniques and, indeed, it proved to be extremely useful in solving the phase problem of X-ray crystallography. We single out this aspect of their work, because it is a beautiful illustration of how experience in one area of research may bring out creative solutions in another. There were also other contributors to the direct methods, and this needs emphasis, because the Nobel Prize often adds shine to the laureates and leaves the other players in the shadow. David Sayre was such a contributor who reviewed the history of solving the phase problem in $\mathrm{X}$-ray crystallography in a beautiful paper [80]. 
The gas-phase electron diffraction technique of molecular structure determination has played a conspicuous role in the history of structural chemistry [47]. It was briefly reviewed when the technique was 75 years old [81]. The new technique emerged in 1930 and over the next decades, it produced a large amount of crucial structural data. Linus Pauling was one of its great initial practitioners who used a great deal of electron diffraction information in writing his classic, The Nature of the Chemical Bond. The triumph of the gas electron diffraction technique is one of many examples to support the notion about the importance of new instruments and techniques in the advancement of science. On the other hand, its history shows a gradual decline over the past two or three decades, paralleled by the rise of computational possibilities. There are still a few groups around, using gas phase electron diffraction, which is an excellent pedagogic tool in structural chemistry. Somewhat oversimplifying, we shine a beam of electrons over a stream of molecules in the experiment, and when a radial distribution appears in the data analysis, bond lengths and other internuclear distances can be directly read off this curve. It is an almost moving moment to show how the structure emerges from an experiment, at least for some of the simplest molecules.

Hauptman and Karle had a fruitful partnership during their cooperation at the Naval Research Laboratory (NRL) in Washington, DC, in working out the direct method. Soon afterwards, their ways parted. Karle spent the rest of his career at the NRL whereas Hauptman continued his activities at the Hauptman-Woodward Medical Research Institute in Buffalo, eventually as its president. Structural Chemistry published two obituaries of Jerome Karle [49, 82], but none of Hauptman, so here we remember him briefly. There is much more about him in the third volume of the Candid Science book series [83].

Herbert A. Hauptman was born in New York City. He received his BS degree from the City College of New York in 1937 and his MA degree from Columbia University in 1939. Then followed a hiatus of 16 years before he became a $\mathrm{PhD}$ for his dissertation titled "An n-Dimensional Euclidean Algorithm" at the University of Maryland. Following his Master's degree, he applied to doctoral programs, but at the time, he was not accepted due to anti-Semitic discrimination. Later, he might have used his contribution to the development of the direct method for a dissertation, but it proved difficult to distinguish Karle's and Hauptman's individual shares in this work. Hence, Hauptman wrote a dissertation on an entirely different topic.

When in the early 1950s, Hauptman and Karle solved the problem of the phase, the community was very reluctant to accept the validity of their discovery. Fortunately, Hauptman and Karle did not have difficulties in publishing their findings, because the Editor of Acta Crystallographica, Isidor Fankuchen (1904-1964), ignored the community sentiment, sent out the submitted manuscripts for review, and published everything Hauptman and Karle submitted. Fankuchen himself was a renowned crystallographer. Joel Liebman reviewed his activities and shared some memories of his own encounters with him from his pre-college time. Fankuchen left a memorable impression on Liebman and impacted the choice of his career path [26]. Coming back to the fate of the direct methods, it took some 10 to 15 years for the crystallographic community to accept them. Once it did, the new approach had a spectacular career. Isabella Karle played a major role in demonstrating the efficacy of Hauptman and Karle's technique in solving actual problems.

The photograph above (Fig. 1) shows Hauptman with a stained glass polyhedral model. Making such models was a hobby for him, which may have developed during a period of his life when the hectic work on the direct methods was over, but the fame was not there yet to interfere with his daily life. Already in childhood, Hauptman was fascinated by geometry and developed a particular interest in the Platonic solids. Around 1980, he attended a class working with stained glass and started making polyhedra from stained glass. The first models were crude, but they kept improving, and over the years, he made about forty regular and semi-regular polyhedra. His artistic inclination and scientific acumen combined, he became interested in packing spheres inside the polyhedra and started publishing papers about his findings. Dealing with icosahedra presented special problems. He faced some challenges that were related to issues that Alan L. Mackay was working on at about the same time and that fell into the realm

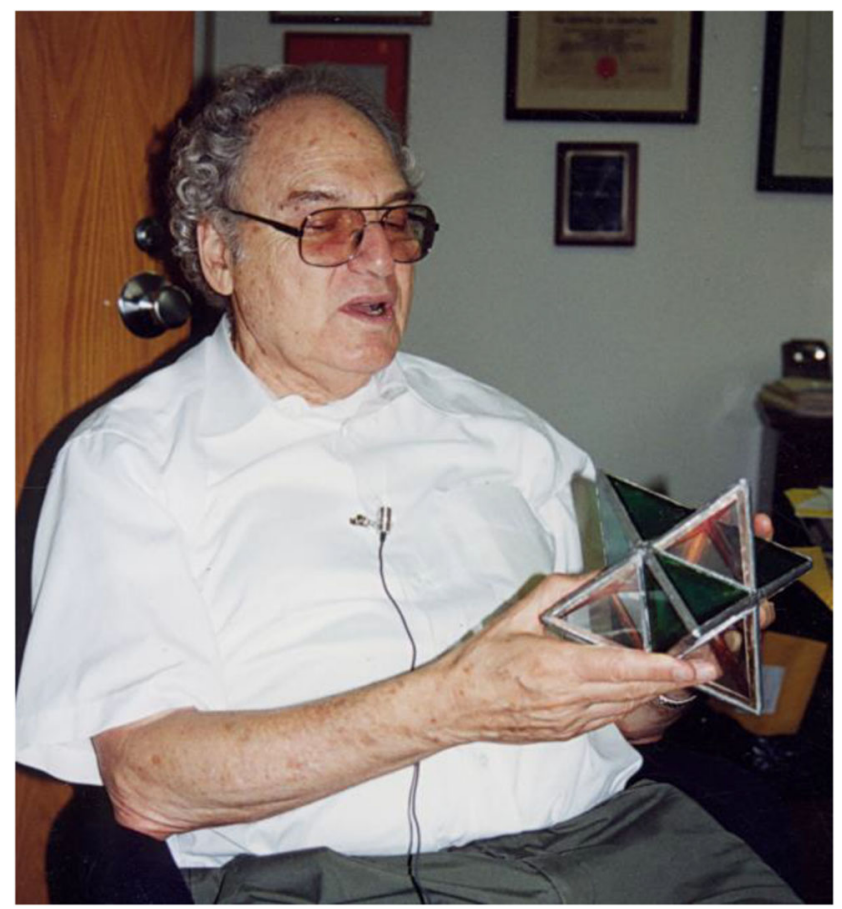

Fig. 1 Herbert A. Hauptman in 1995 in his office in Buffalo with one of his stained glass polyhedron models (photograph by Istvan Hargittai) 
of what Mackay called generalized crystallography (see below). At some point, however, Hauptman stopped working on these problems and stopped making polyhedra. It was the Nobel Prize after which he simply did not have time for his "hobbies" anymore [83].

Early on, Structural Chemistry devoted a whole issue to the structural aspects of nuclear chemistry and the collection of papers was introduced by Edward Teller [2, 72]. In his succinct narrative, he traced back the origin of structural science to the ancient Greeks and charted further developments. He predicted that knowing the chemical structure would provide a better understanding of superconductivity. He ended his foreword by relating the science of life and structural chemistry: "Matter is more complicated than most materialists believe, or even are capable of imagining. What is yet to be discovered about the structure of molecules will contain many surprises. The surprises may not completely suffice to explain the phenomenon of life, but it is a certainty that without those investigations, life cannot be understood" [2].

Teller's involvement with the development of the hydrogen bomb and his political activities have overshadowed his scientific contributions. Yet, he was both an outstanding physical chemist and nuclear physicist. He considered the BET equation more than anything else to be his most important scientific achievement, which is still in use broadly in adsorption studies. As Teller hinted at, the phenomena of superconductivity can be related to the Jahn-Teller effect. This effect has had a rich afterlife and has been the starting point of the recognition of a number of related effects. The origin of the discovery of the Jahn-Teller effect has a rich history, which was presented in this journal based on some detective work [12]. Archival material was examined and relatives of Rudolf Renner in Germany and Hermann A. Jahn in England were contacted. They were very helpful in forming a picture about these two forgotten contributors to this important segment of structural chemistry. Their fates are of interest and it was good to bring them out of Teller's shadow. With fairness, we note that Teller always stressed the contributions of his associates in research. In addition, he singled out Lev Landau's [9] contribution to the discovery of the Jahn-Teller's effect. Here is what he wrote: "This effect had something to do with Lev Landau. I had a German student in Göttingen, R. Renner, and he wrote a paper on degenerate electronic states in the linear carbon dioxide molecule, assuming that the excited, degenerate state of carbon dioxide is linear. ... In the year 1934 both Landau and I were in Niels Bohr's Institute in Copenhagen and we had many discussions. He disagreed with Renner's paper, he disliked it. He said that if the molecule is in a degenerate electronic state then its symmetry will be destroyed and the molecule will no longer be linear. Landau was wrong. I managed to convince him and he agreed with me. This was probably the only case when I won an argument with Landau" $[9,12]$. Teller even suggested that the name of the effect "really should be the Landau-Jahn-Teller theorem because Landau was the first one who expressed it, unfortunately using the only exception where it was not valid" [84].

The successful entrepreneur Stephen Wolfram's book about notable people [78] offers a potpourri of great intellectuals in science whom he calls idea makers. The list includes Richard Feynman, Kurt Gödel, Alan Turing, John von Neumann, George Boole, Charles Babbage and Ada Lovelace, Gottfried Leibnitz, Benoit Mandelbrot, Steve Jobs, Bertrand Russell and Alfred Whitehead, Srinivasa Ramanujan, Solomon Golomb, among others. One of Wolfram's thought-provoking statements refers to Babbage, the early computer developer. It says: "Charles Babbage was an energetic man who had many ideas, some of them good." It is crucial to understand about greatness. It does not matter how many worthless ideas one may produce if there are some good ones among them; they are the ones that count. Linus Pauling was asked how did he produce so many good ideas. He responded that he produced a large number of ideas and threw away the worthless ones. The problem is when the author of a worthless idea insists on it being good and that others should appreciate it and build on it. Marshall W. Nirenberg (1927-2010) compared the process of sorting out ideas to throwing darts at a target on the wall, then ignoring the darts that went astray and keeping the one or ones that hit the bull's eye [85]. The biomedical scientist, who first cracked the genetic code, had many ideas, but he did not weed them out, like Pauling. Rather, Nirenberg recorded his ideas every night in his notebooks and left the notebooks to the US National Library of Medicine.

Nuclear physics, structural chemistry, and biology intersected in the development of magnetic resonance imaging (MRI), one of the most brilliant diagnostic tools of modern medicine. Paul C. Lauterbur (1929-2007) [42] and Peter Mansfield (1933-2017) shared the Nobel Prize in Physiology or Medicine in 2003 for their contributions to this great advancement. Both had a difficult path to the discovery and both showed extraordinary dedication and perseverance. Some differences in their paths are of interest to note. Lauterbur did not succeed in patenting his inventions, whereas Mansfield was very successful in that. Mansfield spent the rest of his life working on the further development of MRI using the financial background of his patents. In contrast, Lauterbur moved to a different area, the understanding of the origin of life, a subject that had fascinated him from his youth.

Structural molecular biology was a great success story of the twentieth century and it continues in the twenty-first, bringing benefits to humanity in personalized medicine and elsewhere $[68,71]$. Much of the advances have happened, thanks to the progress in research instrumentation in which $\mathrm{X}$-ray crystallography and the different kinds of chromatography lead the pack. However, progress was not always straightforward. The chemistry of proteins and nucleic acids appears 
to be especially glamorous, but this was not always so. Looking back on his career in science, Vladimir Prelog (1906-1998) remembered, for example, that chemists "considered the nucleic acids as dirty mixtures that we could not and should not investigate with our techniques" [4]. Plenty of recognition have gone for discoveries in the life sciences incorporating much what could also qualify as chemistry and structural chemistry [70].

There was a time when carbohydrates attracted much more research in chemistry than other biological macromolecules. The Nobel laureate Baruch S. Blumberg was distinguished for the discovery of the hepatitis B virus and the vaccine to prevent infection with it. However, in his early career, he was much involved with carbohydrates and investigated the physical chemistry of polysaccharides [48]. Torvard C. Laurent made fundamental discoveries on polysaccharides and in particular on hyaluronic acid. He was one of the small group of scientists who introduced the name hyaluronan for hyaluronic acid [46]. Phoebus A. Levene (1869-1940) was a universal biochemist who distinguished himself in both research and mentoring generations of future leaders in biochemistry. $\mathrm{He}$ had results in the chemistry of proteins, nucleic acids, carbohydrates, and other biological macromolecules. It seems unfair that he is most remembered for his erroneous tetranucleotide hypothesis, which he established in 1909 and kept refining for the next 30 years [13]. According to this hypothesis, there would be a regular, repeating order of the nucleotides in the nucleic acids, making them dull and incapable of carrying the information of heredity. Part of the reason for Levene's mistaken conclusion was the unsophisticated state of chromatography at his time, yielding unreliable results of analyses.

It was the great progress in the technique of chromatography that helped Erwin Chargaff (1905-2002, Fig. 2) to arrive at one of his two great discoveries - that the composition of nucleic acids is organism-specific [3]. His other great discovery was the observation of base-pairing, which was crucial for Watson and Crick's suggestion of the double-helix structure of deoxyribonucleic acid (DNA). Coming to the conclusion of base-pairing was especially brave on Chargaff's part. His data on the nucleic acids scattered considerably and he had to overcome a justified hesitation whether or not his observation of the regularity was real or imagined. Today, the knowledge of base-pairing in DNA is part of our scientific culture, but proposing it for the first time and on the basis of not very convincing data was the act of a true pioneer. Alas, Chargaff did not follow up this act by posing the question of "why?" and missing this follow-up must have contributed to his bitterness so much displayed during the rest of his long life. Seeking the answer to the question "why?" always facilitates understanding observations. Linus Pauling joined the quest for the structure of DNA rather belatedly. He proposed a triple-helix structure, but as soon as it was published, it was seen to be

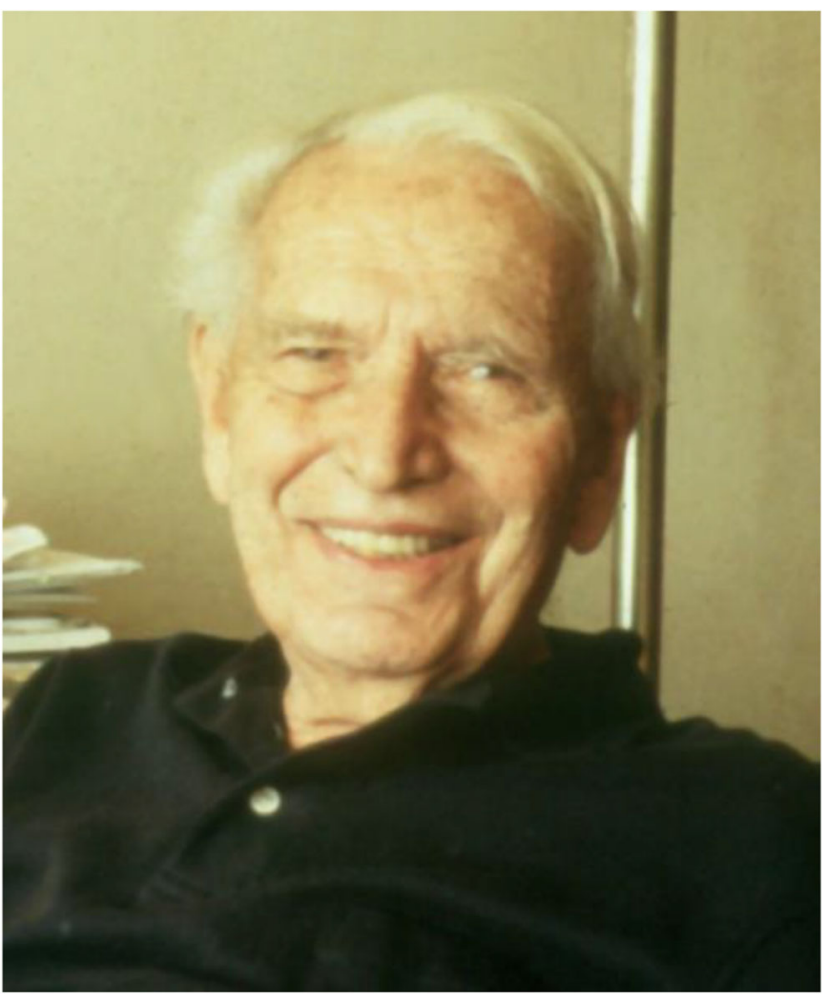

Fig. 2 Erwin Chargaff in 1994 in his Central Park West home in New York (photograph by Istvan Hargittai)

erroneous. A triple helix could have not yielded a meaningful response to the question "why?". Of course, it is easy to come up with the right questions in hindsight - and the right question may be more difficult to formulate than finding the right answer. When Watson and Crick proposed the double helix, and it was a suggestion rather than a certainty, they could be reassured by the appropriateness of such a structure for the possible copying mechanism in the transfer of the genetic information [29, 38]. The final certainty came only when Maurice Wilkins completed his elaborate X-ray diffraction studies by the early 1970s [59]. There was no doubt though in the validity of the original double helix and this was manifested by the Nobel Prize in 1962 to Watson, Crick, and Wilkins. We cannot know whether or not Rosalind Franklin might have received the Nobel Prize for her work because by the time of the Nobel for the DNA structure, she had been dead for years. At the time of the Nobel though, the true value of her discoveries was not yet clarified; today, we are aware of her decisive contribution.

The creation of monoclonal antibodies was one of the many later developments of the spectacular progress in molecular biology. César Milstein (1927-2002) and Georges Köhler (1946-1995) [63] received each one-third of the Nobel Prize in Physiology or Medicine in 1984. The remaining third went to Niels K. Jerne for his discoveries in immunology. The joint formulation of the motivation for the award was, "for theories concerning the specificity in development 
and control of the immune system and the discovery of the principle for production of monoclonal antibodies.” Köhler was Milstein's postdoctoral associate in Cambridge, and Milstein did all what he could to ensure that the anticipated Nobel recognition would include his co-worker. Untimely death then prevented Köhler to reach further heights in science.

Linus Pauling wrote himself into the annals of the history of science with his uncovering of the nature of the chemical bond and the discovery of the alpha-helix of proteins [15, 52]. He worked intensively on the structure of proteins in the 1930s. He took up the topic again in 1948, following a decade-long hiatus. It was still at the time when proteins seemed to be so much more probable for carrying the information of heredity than nucleic acids. Pauling could pause for a decade in his study of the protein structure as he waited for better tools to continue it. Phoebus Levene could spend time refining his hypothesis of the nucleic acid structure for three decades. These are examples of the leisurely pace of these crucial investigations that would not be possible today. What appeared to be a beautiful icon for modern science- the double helix - very soon became the starting point of revolutionary changes in medicine. There was first the race for the discovery of the cipher of how information transfers from the nucleic acids to the proteins (called by the misnomer, the genetic code). When this became available, it was followed by the Human Genome Project $[51,68]$.

The periodic table of the elements is also a science icon [7, 37, 75, 77]. Dmitry I. Mendeleev has become the best known of its discoverers. He has a great cult in his home country, Russia, but this has developed since his demise. He was much less recognized in his lifetime. In the two-tier system of membership of the Russian Academy of Sciences, he reached the corresponding member statues, but although he was nominated, was never elected to full membership. Similarly, he was nominated, but never awarded the Nobel Prize. Mendeleev's fame has not suffered from these omissions whereas the prestige of the Russian Academy and the institution of the Nobel Prize has. Mendeleev had a broad-based circle of activities. He was an outstanding pedagogue and his system of elements originated from his preparations for his general chemistry lectures.

Similarly, the discovery of the first noble gas compound by Neil Bartlett (1932-2008, Fig. 3) stemmed from his preparations for his lectures. Just as he was teaching ionization potentials, it struck him how similar the ionization potentials of the oxygen molecule and xenon were. This gave him this idea: if it was possible to prepare $\mathrm{O}_{2} \mathrm{PtF}_{6}$, then it should be possible to prepare $\mathrm{XePtF}_{6}$. This is exactly what happened [14]. In hindsight, this appears simple, but sometimes the simplest ideas bring great discoveries about. Nobody had succeeded to prepare any noble gas compound before, and these elements used to be called inert gases. Bartlett's brief

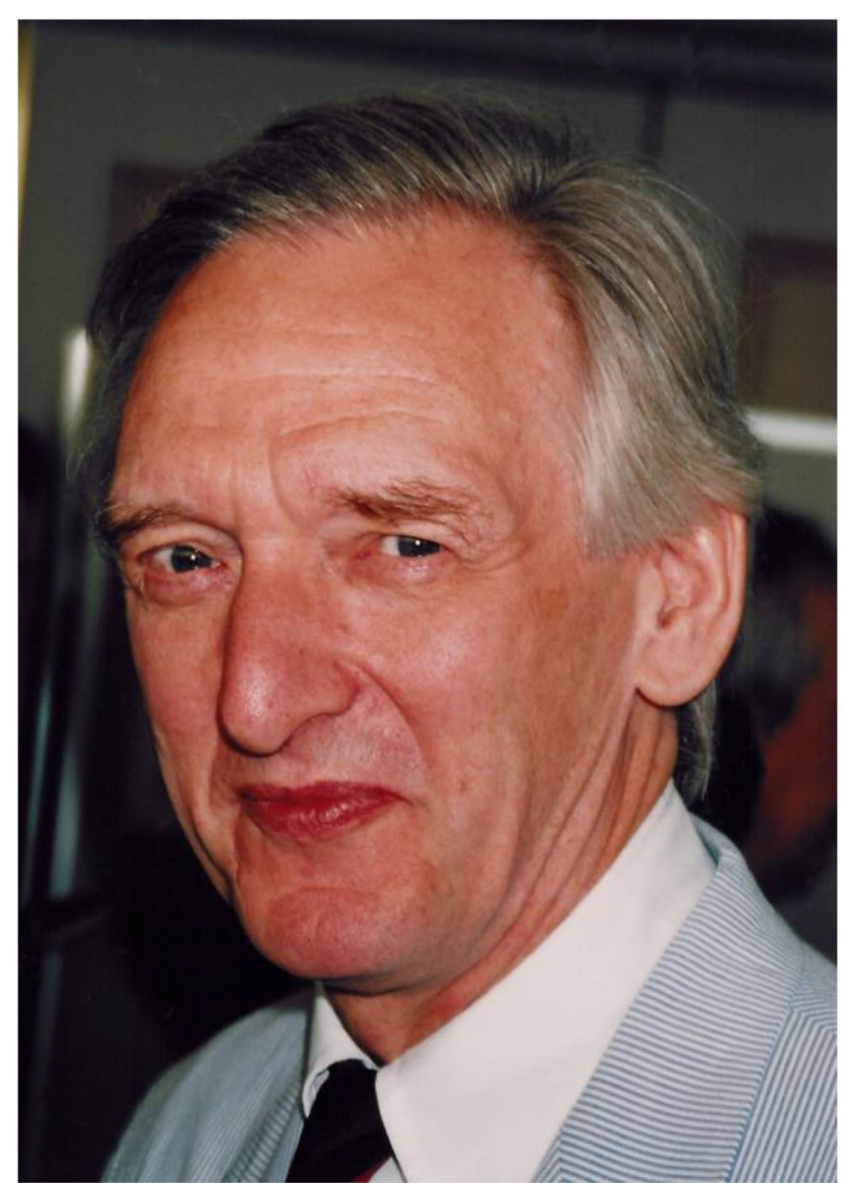

Fig. 3 Neil Bartlett in 1994 at the International Symposium on Fluorine Chemistry in Yokohama, Japan (photograph by Istvan Hargittai)

communication appeared in June 1962, and still during the same year, several other laboratories succeeded in the preparation of further noble gas compounds. Once it was known that this was possible, the researchers no longer were to accept failure in their experiments. Unfortunately, Bartlett did not receive the Nobel Prize for this seminal discovery although, erroneously, many people think he did. That Primo Levi in his famous book The Periodic Table refers to Bartlett's Nobel Prize is quite a distinction.

Most Nobel laureates in the sciences are outstanding discoverers. It seldom happens that somebody receives this award undeservedly $[20,21,35]$. Conversely, many who deserve it are missing from the roster of the Nobel laureates. Mendeleev's is certainly such a case, perhaps, the most conspicuous in chemistry. Neil Bartlett's is another one. The decisions are never easy [34]. It is the highest recognition in science, or, almost the highest. At the time of the discussion about whether or not element 106 should be named after Glenn T. Seaborg, he declared that he would readily give up his Nobel Prize for getting element 106 named after him [11].

Structural chemistry has benefited much from the progress in physics, both in instrumentation and in understanding the 
underlying interactions that determine structure. Over the years, a number of topics of nuclear physics, atomic physics, the physics of fundamental particles, and the development of quantum mechanics figured in the journal. The apropos were anniversaries of great physicists or the publication of important monographs. Many of the physicists whose names signal seminal discoveries had made remarkable discoveries directly relevant to chemistry as well. Suffice it to mention the contributions of Eugene P. Wigner (1902-1995) whose mentor for his doctoral work was Michael Polanyi (1891-1976) - at the time a renowned physical chemist $[30,65]$. This qualifier is needed, because Polanyi graduated as a medical doctor, then, turned into a physical chemist, and at some point switched to philosophy. He was also a great pedagogue who mentored Wigner, in Berlin, and later, Melvin Calvin (1911-1997) in Manchester. Polanyi was a lonely discoverer, par excellence. All discoverers are lonely because for some time they know something what no other does. This loneliness is then eased when the discovery becomes known by others, gets accepted, and serves as starting point of further discoveries. For Polanyi, this seldom happened because most of his discoveries were premature discoveries, whether they were in his adsorption studies or in his X-ray crystallographic experiments on noncrystalline materials - fibers. At some point, he made one more move and switched to philosophy, an internationally renowned one, especially in epistemology.

The physics and chemistry-oriented physics mentioned above have been represented on the pages of Structural Chemistry by parity violation [6]; the scientists who were involved in taming nuclear energy [8, 24]; Kai Siegbahn, the co-inventor of high-resolution electron spectroscopy [45]; Ludwig Boltzmann, who developed statistical mechanics and linked the atomic properties to the properties of matter [53]; particle physics - today referred to more as the physics of fundamental particles [58,60]; Max Born and the birth of quantum mechanics [62] and some aspects of the birth of quantum chemistry [69]; and the physics of strong interactions [66]. These huge chapters of science are represented merely by brief obituaries and book reviews. Nonetheless, even in a small volume of writing, a great deal of human drama may be crammed. An example is the contrast between the fates of Max Born [62] and Erich Hückel [69]. Born was chased out of Germany after Hitler's accession to power whereas the reign of National Socialism benefited Hückel's career.

Materials science is at the border of traditional physics and chemistry. There have been outstanding inventions in this area of science, which is closely related to applications. The Belgian-born American chemist, Leo Baekeland (18631944), introduced a new class of large molecules in the 1900 s, at a time when and for a long time even afterwards, still many questioned the existence of giant molecules. Baekeland was a founder of the plastics industry with his invention Bakelite, the first thermosetting plastic [74].
Materials science demonstrated profound progress during the last decades of the twentieth century. High-temperature superconductivity, the fullerenes [39], graphene [16], quasicrystals [19, 22, 28], and conducting polymers [43] signal this progress. In each of these cases, a Nobel Prize demonstrated that there was sufficient publicity to heighten the expectations.

The discovery of quasicrystals was the latest and it indeed was rather late in receiving this recognition. The reason was Linus Pauling's resistance to accepting the interpretation of Dan Shechtman's (1941-, Fig. 4) observation [19, 22, 28]. In his time, in his uncovering of the structure of proteins, Pauling appeared to be the maverick who did not let dogmas shackle him and his imagination. Now, he appeared denying the next generation of researchers their turn to question the validity of an old dogma of classical crystallography. Ultimately, Shechtman's interpretation of his observations won over the scientific community and even the definition of what a crystal is had to be changed. The quasicrystal discovery and the evaluation of its significance raised an interesting philosophical question. Was it a trend-setting discovery introducing a paradigm change, or did it become conspicuous because the definition was too narrow of what a crystal is. In other words, was it the original carelessness that made the observation of what we call quasicrystals stand out? The tremendous success of early X-ray crystallography stemmed

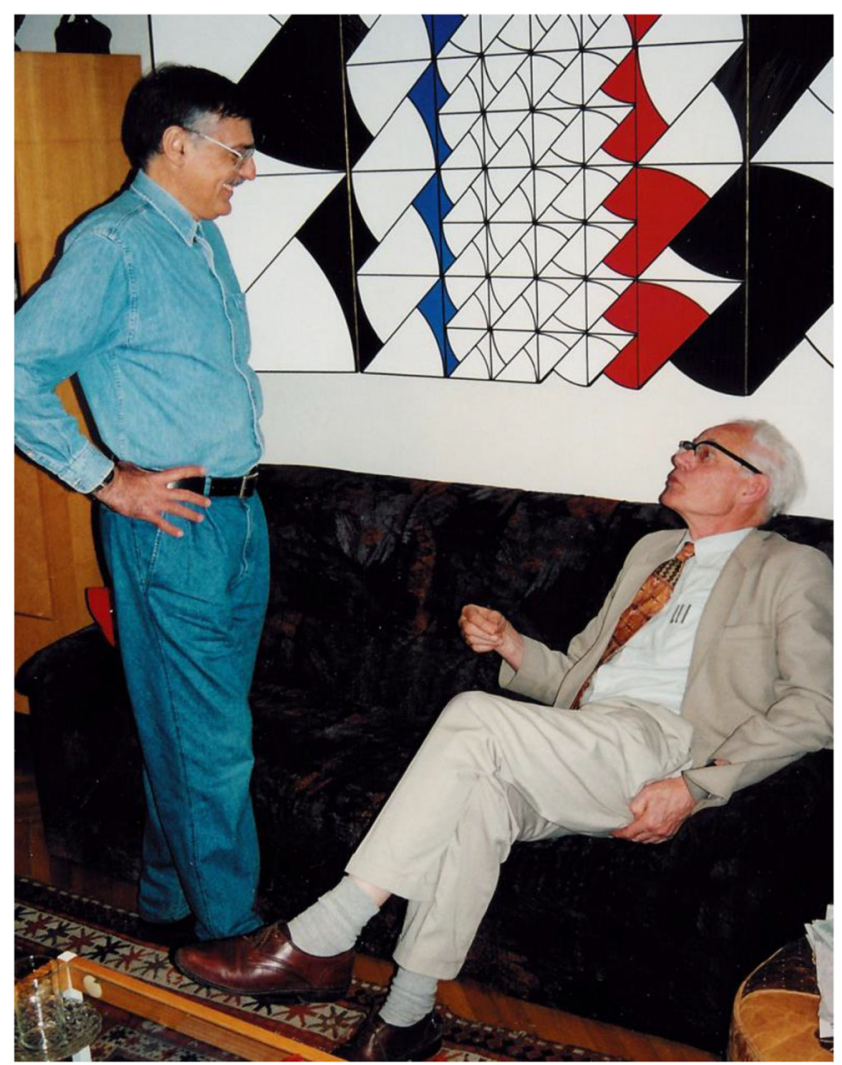

Fig. 4 Dan Shechtman (left) and Alan L. Mackay (right) in 1995 in the Hargittais' home in Budapest (photograph by Istvan Hargittai) 
from the investigation of regular and periodical structures, and this indeed narrowed the field of what we now call classical crystallography [25, 36, 40, 61]. Even before Shechtman's observation, there were numerous signals of the existence of many more structures that would not fit classical crystallography. Fivefold symmetry, as tenfold, and others, are impossible according to the rules of classical crystallography. Yet J. Desmond Bernal examined the possibility of fivefold symmetry in the condensed phase [64]. Alan L. Mackay (1926-, Fig. 4), over the years, published accounts of "generalized crystallography" extending classical crystallography much beyond its limits [31, 32]. He even simulated a diffraction pattern in 1982, to which Shechtman's electron diffraction pattern showed uncanny similarity. The significance of many of the seminal discoveries in science might be ascribed to the "carelessness" of original definitions. To carry this approach to the extreme, should the possibility of quantum mechanics been somehow considered in the original definition of mechanics? The discovery of quasicrystals did bring a paradigm change about and did so in a rather spectacular manner. Structural Chemistry has strongly cultivated the aspects of crystallography that fall into the non-traditional domains. This is seen in the many relevant papers published over the years and in the special volume highlighting such contributions [86].

Organic chemistry has always been a fruitful and fertile area for structural chemistry where challenges and answers came about and discoveries were made from structural considerations. It was always a challenge to interpret structurally what was observed in the laboratory. In the 1950s, such interpretations received political significance when the theory of resonance was labeled reactionary in the Soviet Union. This was almost unbelievable for the chemists outside of the Soviet empire, but there it was real. Internationally renowned scientists could lose their jobs merely for supporting, let alone, using this theory in their work. There was an overwhelming fear of Western influence in the paranoid Soviet establishment. Only the classical teachings of the Russian Aleksandr M. Butlerov (1828-1886) were acceptable [18]. This was at a time when most discoveries in science were assigned some Russian discoverer in the Soviet Union. Because of Pauling's role in creating and disseminating the theory of resonance, he was also declared to be a great enemy. This hostility lasted until Pauling's leftist politics and friendliness toward the Soviet Union had become known. The overzealous approach to the priority issue has hindered the recognition of real priorities by Russian and Soviet scientists although there have been plenty of original discoveries for which there could be justified claim. An example is the discovery of multiple metalmetal bonds by Ada Kotelnikova at the Kurnakov Institute of Inorganic Chemistry in Moscow. The work though had been discontinued there and was picked up and brought to fruition by F. Albert Cotton in the USA [41].
H.C. Brown (1912-2004) developed an extensive field of boron organic chemistry, which proved to be most rewarding for him [23]. When he was a graduate student, his fiancé gave him a book about boron chemistry as a graduation present in 1936. She was a fellow chemistry student and her choice of the book was more dictated by its low price than its chemistry (which, by the way, represented highly interesting science; it was Hydrides of Boron and Silicon by Alfred Stock). Brown's boron chemistry was awarded by a share of the Nobel Prize in 1979. He had been interested in the mechanism of chemical reactions from his student years. This interest got him into a fascinating debate with one other highly visible organic chemist, Saul Winstein. The debate was about the mechanism of a reaction and they both based their considerations on the same experimental results that nobody disputed. The debate was of interest not only for its science but also as a spectacle. The two colorful participants ensured some entertainment at conferences for years. The reagents and the products of the reaction were identified unambiguously, and the question was about the intermediates that were short-lived. Their nature remained a mystery until a heretofore unknown chemist claimed that he had identified them and could resolve the controversy.

George A. Olah (1927-2017), a recent immigrant from Hungary, was that young chemist [33]. He gave longer life to the reaction intermediates by stabilizing them with the help of some extremely strong acids - superacids - and decided the long-lasting debate. This deed ensured Olah a fame that without the Brown-Winstein debate could have been impossible to gain. However, Olah's true contribution to chemistry of lasting value can be summarized as follows: He realized that the electron donor ability of shared electron pairs can rank equal in importance with the electron donor ability of unshared (or lone) electron pairs. The electron donor ability of the shared electron pairs can be induced by the presence of superacids. This meant that the carbon-carbon and carbonhydrogen bonds could be made into reactive entities, and this led to the creation of a whole new area in hydrocarbon chemistry and countless new substances. Olah distinguished himself in conducting his research in cooperation with representatives of many techniques of structure determination with great weight among them of computational studies [50]. The once dull hydrocarbon chemistry, thanks to Olah's discovery, became an exciting field. The superacids thus played a decisive role in his discovery. Their history goes back to James B. Conant (1893-1978) who coined the name of superacids in 1927 and to Ronald J. Gillespie (1924-) who defined superacids in the 1960 s as protic acids stronger than $100 \%$ sulfuric acid. The investigation of superacids was one of Gillespie's two main interests; the other was modeling molecular structures. He is best known for the Valence Shell 
Electron Pair Repulsion (VSEPR) model of molecular geometry $[10,87]$.

Many researchers work at universities and being a mentor may be part of their career. An outstanding researcher may not be necessarily an outstanding mentor and an outstanding mentor may not be necessarily an outstanding lecturer. Eugene P. Wigner served as mentor to the three leading figures of American condensed state physics, but his lecturing style was not very captivating. He was constantly worried whether or not all students attending his lecture might understand what he was talking about, and this interfered with the flow of his lecturing. Throughout his life, he gratefully remembered how good of a mentor Michael Polanyi was for him. Polanyi taught him that "science begins when a body of phenomena is available which shows some coherence and regularities, that science consists in assimilating these regularities and in creating concepts which permit expressing these regularities in a natural way." [88].

For Frank Westheimer (1912-2007), James B. Conant should have been his doctoral mentor. However, Conant could not be, due to his other obligations. Still, a comment by Conant to Westheimer accompanied him throughout his career and he measured every move he made whether or not Conant might have approved [44]. Westheimer completed a brilliant career. He was a pioneer of molecular mechanics, had interest in understanding steric effects, made discoveries in the stereochemistry of enzymatic action in biochemistry, and was one of the rare organic chemists who was at home in physical chemistry as well. Besides, he did outstanding community service by chairing a committee in the 1960 s, which produced the report for the National Academy of Sciences, "Chemistry: Opportunities and Needs," better known as the Westheimer Report.

The disadvantaged situation of women characterizes many areas of human activities, and this includes chemistry as well, though perhaps some areas fare better than most others. In crystallography, for example, there have been a number of outstanding women contributors, perhaps because the conditions of research better accommodated the double challenge of family and laboratory [73]. Much depends also on the availability of role models in attracting gifted young women to science, and Marie Curie has been such a role model for many [17]. Sidestepping Lise Meitner (1878-1968) for the Nobel Prize is not a bright chapter in the annals of the institution of the Nobel Prize. Meitner's case was made yet harder by her Jewishness [67]. Even anti-Nazi German scientists, such as Otto Hahn (1879-1968), placed German pride before universal fairness when they were trying to rebuild German science after the devastation caused by National Socialism and its consequences.

Carl Djerassi (1923-2015) was a most versatile scientist [77] (Fig. 5). He was a holder of the US National Medal of Science and the US National Medal of Technology,

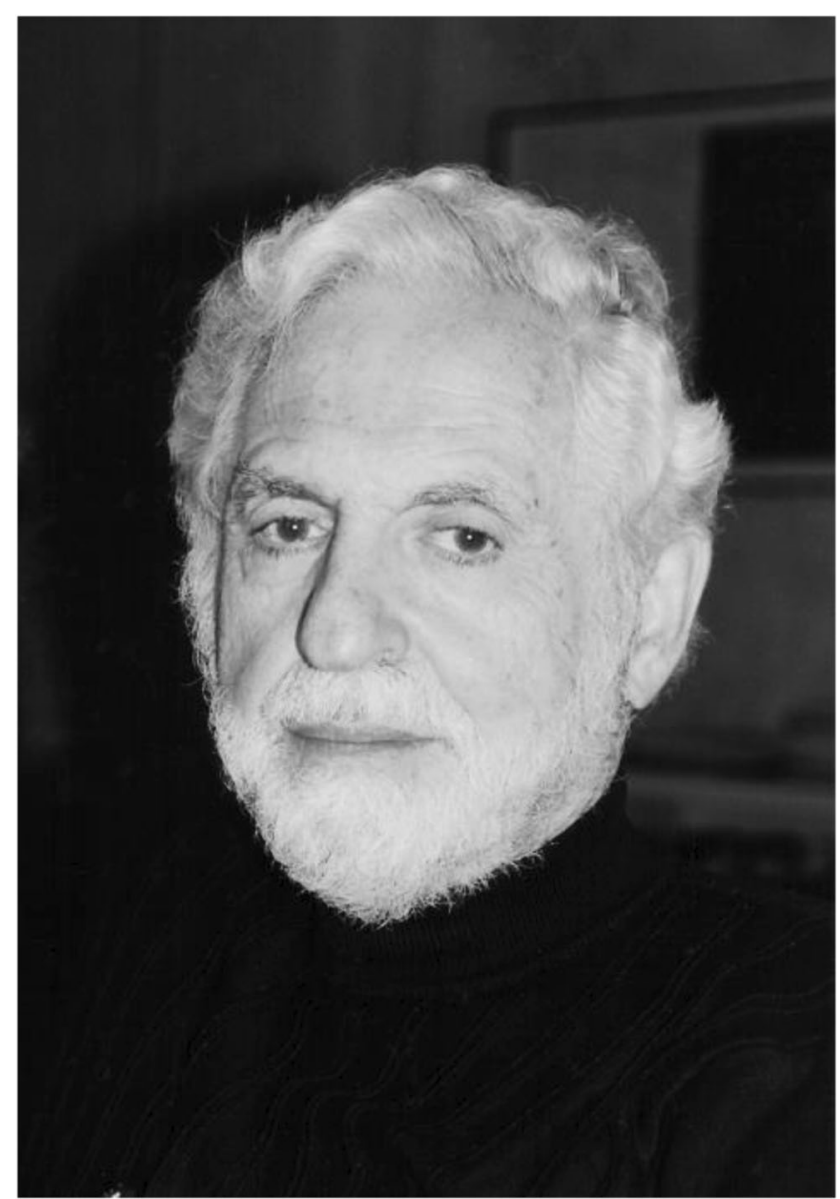

Fig. 5 Carl Djerassi in 1996 in his home in San Francisco (photograph by Istvan Hargittai)

already an unusual double honor. He could have received a similar recognition for his literary activities as a poet and playwright. He was a true pioneer in chemistry when he embarked on his studies in the structure elucidation of organic substances, and he much contributed to the application of physical techniques in this field, among them ultraviolet spectroscopy, infrared spectroscopy, NMR spectroscopy, mass spectrometry, the chiroptical techniques, electron spin resonance spectroscopy, and others. When the application of physical technique had become routine, he extended his activities to computer-aided structure elucidation. On the chemistry side, he was much involved in the investigation and application of steroids, was one of the creators of "the Pill," and was one of the initiators of marine natural products chemistry (the other was Paul Scheuer). He published autobiographies (yes, not just one, but more, as time was passing), wrote poetry, novels, and his dramas have been staged with success, at least for science-literate audiences. He always stressed that his mission was to show science in fiction (which is important to distinguish from science fiction). 
It is a beautiful project on the part of the American Chemical Society to commemorate important discoveries, even trend-setting individual papers, by memorial plaques, and not only in the USA, but internationally. Those erected in New York City were collected and described [27], which was no small feat as at the time there was no information about some of the plaques. They had to be found by a detective-like chase. The collection of the ones in New York was part of the creation of a guide book to the memorials of science and scientists in this great city [89]. The memorial plaques honor the foundation of the American Chemical Society and John W. Draper; Havemeyer Hall of Columbia University; the achievements of researchers of nucleic acids and proteins at Rockefeller University; the discovery of deuterium; Oswald Avery at al.'s 1944 paper in the Journal of Experimental Medicine, which established that DNA was the substance of heredity; Bruce Merrifield's paper reporting the new method of solid-phase peptide synthesis; Herman F. Mark's discoveries in polymer chemistry and the achievements in polymer science at the Polymer Research Institute; and the development of deep-tank fermentation technology in 1944, which was followed by the establishment and opening of the world's first large-scale penicillin facility on March 1, 1944. It was still in time to save numerous lives during the last segment of World War II.

For a couple of years toward the end of his long life, the noted physical chemist Kenneth J. Laidler (1916-2003) was an active reviewer of books for Structural Chemistry [54-57]. He was born in Liverpool, England, and earned his M.A. and D.Sc. degrees in physical chemistry under the mentorship of Cyril N. Hinshelwood at Oxford University. He moved to the USA in 1938 and continued his studies at Princeton University, receiving his $\mathrm{PhD}$ degree under Henry Eyring's mentorship in 1940. Throughout his entire career, he was involved with reaction kinetics and already in 1941 he coauthored a successful kinetics text with Eyring and Samuel Glasstone. Laidler worked for the Canadian government in England during and after World War II. In 1955, he became a professor of chemistry at the University of Ottawa from which he retired in 1981, but continued his involvement with the University. He published a number of books on kinetics and his last two books, both appeared posthumously, were about the universe. The books he reviewed for Structural Chemistry were about delusion and fraud in science [54], the universe [55], discoveries [56], and about Darwin and evolution [57].

Over the years, many individuals have appeared on the pages of Structural Chemistry. The impression may form that scientists like to communicate about their science, but seldom would be willing to prognosticate. Nikolai N. Semenov $[5,90]$ and Glenn T. Seaborg $[11,91]$ were exceptions. In 1965, Semenov found it increasingly difficult to delineate various sciences and especially physics from chemistry and biology from chemistry. There used to be a saying that the difference between physics and chemistry was that physics dealt with dirty materials but operated with clean techniques and chemistry dealt with clean materials but operated with dirty techniques. By 1965, this comparison was no longer valid. As far as biology was concerned, it became impossible to conduct serious research in biology without chemistry. Semenov considered biological structure to be a higher order chemical and physical structure and the investigation of chemical processes was highly complex. The chemical reactions in the living organism happen at body temperature, whereas in industry similar reactions sometimes require extreme conditions. Also, whereas proteins are produced in the organism in minutes, in industry, it is a lengthy procedure. The catalysts, called enzymes, make the great speed possible. Once we learn from nature more about the mechanism of enzyme action, there will be another industrial revolution. Semenov used the utilization of solar energy as an example whose efficiency pales in comparison with the efficiency of the photosynthesis in the living organism. There, again, learning from nature would help us to enhance the efficiency of the utilization of solar energy. Semenov mentioned two directions for distant perspectives. One was the classification of elementary particles (today the name more often used is fundamental particles) and through it to learn about the fundamental organization of matter. The other direction, the investigation of matter of higher organization: crystals, semiconductors, and many others - in the final account, the most organized of all, the living matter. Again, these were his views in 1965.

Glenn T. Seaborg (Fig. 6) in 1998 noted the progress in the chemistry for the life sciences and prognosticated for a few years hence [91]. His thoughts for the more distant future were of especially great interest. He did not define how far ahead he thought, but the impression is that he did not try to limit what he might have thought would be valid in his predictions. He stressed the importance of public attitudes toward ethical and human values in evaluating science and the direction research would be taking. In this, research might not be allowed if the potential harmful impact might outweigh the expected benefits. We may add that this would constitute a break with past attitude according to which science goes wherever its development takes it. Then, it is the task of society or its elected representatives to choose how and whether or not to utilize the results. According to Seaborg, further research might be prejudged before embarking on it in such areas as energy resources and technologies, biological research, aircraft development, and social sciences and education. He foresaw conflicts over the tasks of science in the future in a democratic society with growing activism and advocacy of the population. This is an important point, perhaps, a caveat that should not be taken for granted - we might insert. Seaborg seems to have assumed democratic conditions at large, but warned of the dangers of the possible impact of, and this he put in 
Fig. 6 Glenn T. Seaborg (right) and Istvan Hargittai (left) at the Springer booth during the spring 1995 Anaheim meeting of the American Chemical Society (photograph by an unknown photographer)

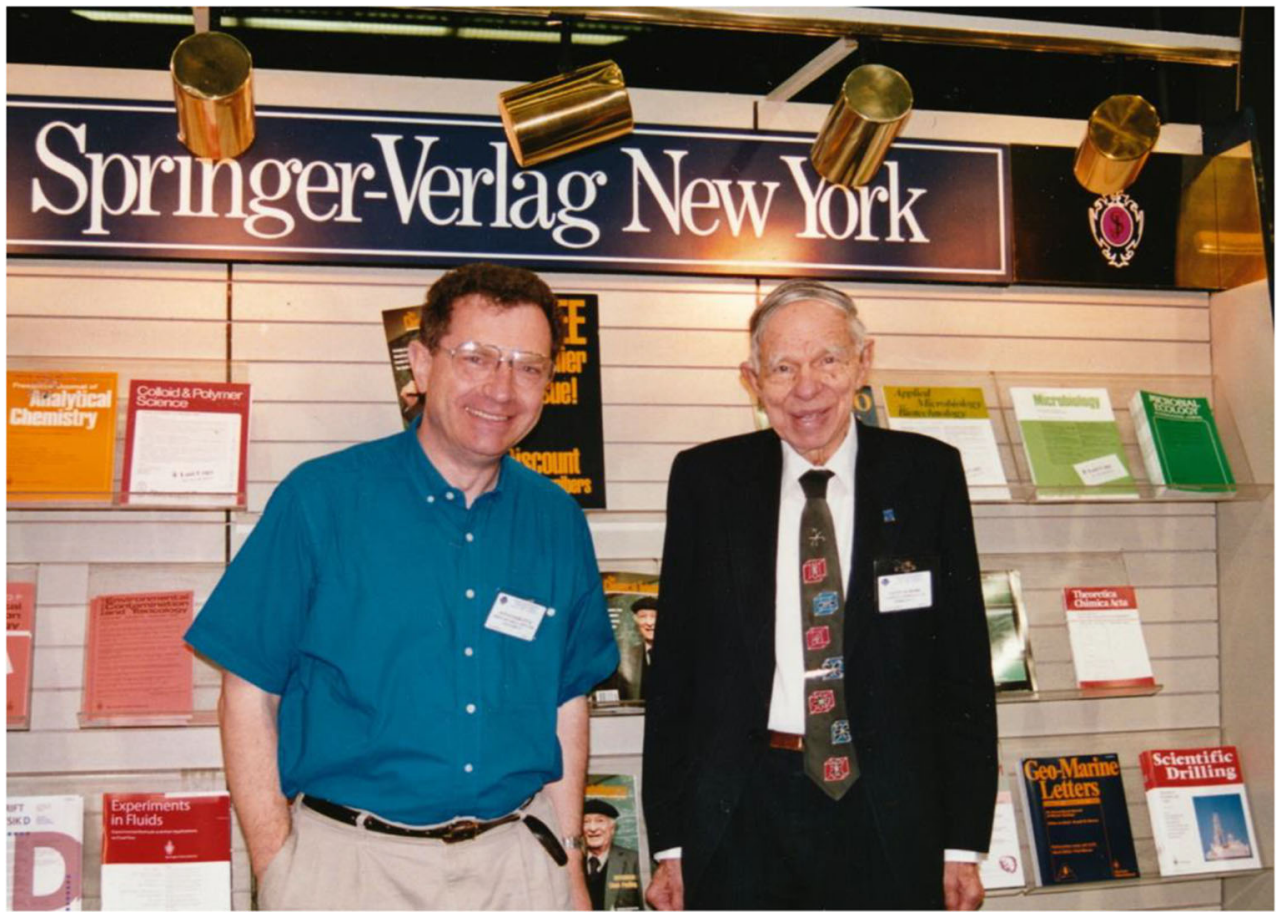

quotation marks, "tyranny of parochial interest," for whose avoidance society must find the way.

When it comes specifically to the future of chemistry, Seaborg stressed two directions. He did not think progress could or should be boundless. Rather, boundaries should be established, and the operations should be kept within them. Three kinds of limitations must be observed that are determined by physical, environmental, and social conditions. It will be our knowledge capital that will allow us to stay within the boundaries in our operations. This knowledge capital is a product of basic research and it must be replenished constantly with new ideas. It is this knowledge capital that is our hope as compensation for the decline of the physical capital and for the higher costs of resources. Seaborg considers it a false notion that science is bringing us toward a society of diminishing problems and risks. Rather, the state of dynamic situation wrought with problems is here to stay. Even there would be a society in a steady state and equilibrium among population, resource, and energy, it would not be without challenge. "There always will be change and creative growth that will challenge the human intellect. There always will be dangers, risks, and increasing responsibilities that will drive us toward a new level of excellence in all we do or try to achieve. This is the progress of human evolution at work, a process that started with man's ascendancy and will continue for some time" [91]. Seaborg's optimism shines through these words he committed to paper only months before his passing. We should gain some confidence from them in the difficult time when we are reading his words in 2020.
Funding Open access funding provided by Budapest University of Technology and Economics.

Open Access This article is licensed under a Creative Commons Attribution 4.0 International License, which permits use, sharing, adaptation, distribution and reproduction in any medium or format, as long as you give appropriate credit to the original author(s) and the source, provide a link to the Creative Commons licence, and indicate if changes were made. The images or other third party material in this article are included in the article's Creative Commons licence, unless indicated otherwise in a credit line to the material. If material is not included in the article's Creative Commons licence and your intended use is not permitted by statutory regulation or exceeds the permitted use, you will need to obtain permission directly from the copyright holder. To view a copy of this licence, visit http://creativecommons.org/licenses/by/4.0/.

\section{References}

1. Hauptman HA (1990) History of X-ray crystallography. Struct Chem 1:617-620

2. Teller E (1991) Foreword. Struct Chem 2:vii

3. Hargittai I (2005) Chargaff centennial: Erwin Chargaff (19052002). Struct Chem 16:455-456

4. Hargittai I, Hargittai B (2006) Prelog centennial: Vladimir Prelog (1906-1998). Struct Chem 17:1-24

5. Hargittai I, Zasurskaya L (2006) Nikolai Semenov's anniversary. Struct Chem 17:333-335

6. Hargittai M (2006) Fifty years of parity violation - and its longrange effects. Struct Chem 17:455-457

7. Hargittai B, Hargittai I (2007) Dmitri I. Mendeleev: a centennial. Struct Chem 18:253-255

8. Hargittai I (2008) The Martians as chemists (on the occasion of the Teller centenary). Struct Chem 19:3-4 
9. Hargittai I, Hargittai M (2008) Lev D. Landau (1908-1968): in memoriam. Struct Chem 19:181-184

10. Hargittai I (2009) Ronald J. Gillespie; the VSEPR model; and molecular symmetry. Struct Chem 20:155-159

11. Hargittai B, Hargittai I (2009) Glenn T. Seaborg; discoveries; and the capital of knowledge. Struct Chem 20:355-359

12. Hargittai M, Hargittai I (2009) Hermann Jahn and Rudolf Renner of the Jahn-Teller and Renner-Teller effects. Struct Chem 20:537540

13. Hargittai I (2009) The tetranucleotide hypothesis: a centennial. Struct Chem 20:753-7561

14. Hargittai I (2009) Neil Bartlett and the first noble-gas compound. Struct Chem 20:953-959

15. Hargittai I (2010) Linus Pauling's quest for the structure of proteins. Struct Chem 21:1-7

16. Hargittai I (2010) Graphene 2010. Struct Chem 21:1151-1154

17. Hargittai I (2011) Marie Sklodowska Curie and the year of chemistry. Struct Chem 22:1-2

18. Hargittai I (2011) Aleksandr Mikhailovich Butlerov and chemical structure: tribute to a scientist and to a 150 -year old concept. Struct Chem 22:243-246

19. Hargittai I (2011) "There is no such animal ( אין חיה כזו )"-lessons of a discovery. Struct Chem 22:745-748

20. Hargittai B, Hargittai I (2011) Nobel Prize and structural chemistry I. Struct Chem 22:961-964

21. Hargittai B, Hargittai I (2012) Nobel Prize and structural chemistry II. Struct Chem 23:1-5

22. Hargittai B, Hargittai I (2012) Quasicrystal discovery - from NBS/ NIST to Stockholm. Struct Chem 23:301-306

23. Hargittai B (2012) H. C. Brown centennial (1912-2004). Struct Chem 23:939-941

24. Hargittai I (2013) Los Alamos and "Los Arzamas". Struct Chem 24:1397-1400

25. Hargittai I (2014) Crystallography in Structural Chemistry. Struct Chem 25:1321-1326

26. Liebman JF (2014) Isidor Fankuchen (1904-1964): more than memories of a master measurer of molecules and materials. Struct Chem 25:1593-1595

27. Hargittai I (2015) ACS memorial plaques in New York City. Struct Chem 26:899-903

28. Hargittai I (2016) From an electron micrograph to a postage stamp. Struct Chem 27:5-7

29. Hargittai I (2016) James D. Watson 88 - the discovery of the double helix was an iconic event in structural chemistry. Struct Chem 27:419-428

30. Hargittai I (2016) Michael Polanyi - pupils and crossroads - on the 125th anniversary of his birth. Struct Chem 27:1327-1344

31. Hargittai I (2017) Generalizing crystallography: a tribute to Alan L. Mackay at 90. Struct Chem 28:1-16

32. Shechtman D (2017) Tribute to Alan L. Mackay. Struct Chem 28: 19

33. Hargittai I (2017) Structures and mechanisms in chemical reactions: George A. Olah's life-long search of chemistry. Struct Chem 28: 259-277

34. Liljas A (2017) Labor pains in the early days of the Nobel Committee for Chemistry. Struct Chem 28:555-561

35. Hargittai I (2017) Structural chemistry author wins Nobel Prize. Struct Chem 28:565-566

36. Massa L (2017) A zigzag path through quantum crystallography. Struct Chem 28:1293-1296

37. Hargittai B, Hargittai I (2019) Year of the periodic table: Mendeleev and the others. Struct Chem 30:1-7

38. Hargittai I (2004) Francis Crick (1916-2004). Struct Chem 15:545546

39. Hargittai I (2006) Richard E. Smalley (1943-2005). Struct Chem $17: 155-156$
40. Hargittai I (2007) Petr M. Zorky (1933-2005): crystal chemist and renaissance scientist. Struct Chem 18:423-425

41. Hargittai M (2007) F. Albert Cotton (1930-2007). Struct Chem 18: $527-528$

42. Hargittai I (2007) Paul C. Lauterbur (1929-2007). Struct Chem 18: $529-530$

43. Hargittai I (2007) Alan G. MacDiarmid (1927-2007). Struct Chem $18: 531-532$

44. Hargittai I (2008) Frank H. Westheimer (1912-2007). Struct Chem 19:361-362

45. Hargittai M (2008) Kai Siegbahn (1918-2007). Struct Chem 19: 363-364

46. Hargittai I (2010) Pioneer of hyaluronan structural chemistry and other studies of polysaccharides: Torvard C. Laurent (1930-2009). Struct Chem 21:471-480

47. Hargittai I, Vilkova AL (2011) A life in structural chemistry: Hommage à Lev V. Vilkov. Struct Chem 22:237-241

48. Hargittai B (2011) Baruch S. Blumberg (1925-2011): Researcher of hepatitis B, polysaccharides, other areas of science. Struct Chem 22:1193-1194

49. Massa L (2013) An appreciation of the life and work of Dr. Jerome Karle. Struct Chem 24:2215-2217

50. Hargittai I (2015) Paul von Ragué (1930-2014). Struct Chem 26:14

51. Hargittai I (2019) Sydney Brenner (1927-2019) — one of the greats of our science on new frontiers. Struct Chem 30:627-632

52. Hargittai I (1990) Linus Pauling. A man and his science. By Anthony Serafini. Struct Chem 1:626-627

53. Laidler KJ (2001) Boltzmann's atom: the great debate that launched a revolution in physics. By David Lindley. Struct Chem 12:465

54. Laidler KJ (2002) The undergrowth of science: delusion, selfdeception and human frailty. By Walter Gratzer; the borderlands of science: where science meet nonsense. By Michael Shermer. Struct Chem 13:99-100

55. Laidler KJ (2002) The universe in a nutshell. By Stephen Hawking. Struct Chem 13:505-506

56. Laidler KJ (2003) Eurekas and euphorias: the Oxford Book of Scientific Anecdotes. By Walter Gratzer. Struct Chem 14:321-322

57. Laidler KJ (2003) Annie's box: Charles Darwin, his daughter and human evolution. By Randal Keynes. Struct Chem 14:423-424

58. Hargittai M (2004) Facts and mysteries in elementary particle physics. By Martinus J. G. Veltman. Struct Chem 15:83-84

59. Hargittai I (2004) The third man of the double helix: the autobiography of Maurice Wilkins. By Maurice Wilkins. Struct Chem 15: 257-258

60. Hargittai M (2005) Understanding the universe: from quarks to the cosmos. By Don Lincoln Struct Chem 16:559

61. Hargittai M (2005) The man, who didn't know to be indifferent: Yuri Timofeevich Struchkov in science and in life (in Russian). By Irena Akhrem and Anton Struchkov, compilers, and many contributors. Struct Chem 16:665-666

62. Hargittai I (2006) The end of the certain world. The life and science of max born: the Nobel physicist who ignited the quantum revolution. By Nancy Thorndike Greenspan. Struct Chem 17:157-159

63. Hargittai I (2006) Köhler's Invention. By Klaus Eichmann. Struct Chem 17:161-162

64. Hargittai I (2006) J. D. Bernal, the sage of science. By Andrew Brown. Struct Chem 17:451-452

65. Hargittai I (2006) Michael Polanyi, scientist and philosopher. By William Taussig Scott and Martin X. Moleski. Struct Chem 17: $551-552$

66. Hargittai M (2007) Fantastic realities: 49 mind journeys and a trip to Stockholm. By Frank Wilczek. Struct Chem 18:733-735

67. Hargittai I (2008) Lise Meitner and the dawn of the nuclear age. By Patricia Rife. Struct Chem 19:371-372 
68. Hargittai I (2010) The human genome project - a triumph (also) of structural chemistry: on victor McElheny's new book, Drawing the Map of Life. Struct Chem 21:667-671

69. Hargittai I (2010) Erich Hückel (1896-1980): from physics to quantum chemistry. By Andreas Karachalios. Struct Chem 21:13151318

70. Hargittai I (2011) Nobel prizes and life sciences. By Erling Norrby. Struct Chem 22:483-487

71. Hargittai I (2011) Present at the flood: how structural molecular biology came about. By Richard E. Dickerson. Struct Chem 22: 741-743

72. Hargittai B (2011) Edward Teller centennial symposium: modern physics and the scientific legacy of Edward Teller. Stephen B. Libby and Karl A. van Bibber, editors. Struct Chem 22:957-960

73. Hargittai M (2011) Chemistry was their life: pioneering British women chemists, 1880-1949. By Marelene Rayner-Canham and Geoff Rayner-Canham. Struct Chem 22:1393-1395

74. Hargittai I (2012) 100+ years of plastics. Leo Baekeland and beyond. ACS symposium series volume 1080. E. Thomas Strom and Seth C. Rasmussen, editors. Struct Chem 23:1659-1661

75. Hargittai I (2012) Ulf Lagerkvist and his Nobel histories. Struct Chem 23:1663-1666

76. Hargittai I (2013) A tale of 7 elements. By Eric Scerri. Struct Chem 24:1781-1783

77. Hargittai I (2014) Carl Djerassi, structural chemist turned author/ playwright, has published a new autobiography, In Retrospect: From the Pill to the Pen. Struct Chem 25:1597-1600

78. Hargittai I (2016) Idea makers: personal perspectives on the lives \& ideas of some notable people. By Stephen Wolfram. Struct Chem 27:1865-1867

79. Karle I, Karle J (2005) Gas electron diffraction and its influence on the solution of the phase problem in crystal structure determination. Struct Chem 16:5-16

80. Sayre D (2002) X-ray crystallography: the past and present of the phase problem. Struct Chem 13:81-96
81. Hargittai I (2004) Looking back and ahead: gas-phase electron diffraction at 75. Struct Chem 16:1-3

82. Hargittai I, Hargittai M (2013) Jerome Karle (1918-2013)—Nobel laureate; charter member of the editorial board of structural chemistry. Struct Chem 24:2219-2222

83. Hargittai I (2003) Chapter 21, “Herbert A. Hauptman,”. In: Hargittai M (ed) Candid science volume III: more conversations with famous chemists. Imperial College Press, London, pp 292 317

84. Hargittai M, Hargittai I (2004) Chapter 21, "Edward Teller,". Candid science iv: conversations with famous physicists. Imperial College Press, London, pp 404-423

85. Hargittai I (2004) Our lives: encounters of a scientist. Akadémiai Kiadó, Budapest, p 25

86. Hargittai I, Hargittai B (eds) (2015) Science of crystal structures: highlights in crystallography. Springer, Berlin

87. Gillespie RJ, Hargittai I (2012) The VSEPR model of molecular geometry. Dover Publications, reprint edition; original publication, 1991, Allyn \& Bacon, New York

88. Wigner EP (1963) City Hall Speech—Stockholm, 1963. Symmetries and reflections: scientific essays. Indiana University Press, Bloomington, pp 262-263

89. Hargittai I, Hargittai M (2017) New York scientific: a culture of inquiry, knowledge, and learning. Oxford University Press, Oxford

90. Hargittai I (2001) Chapter 37, "Nikolai N. Semenov,". In: Hargittai $\mathrm{M}$ (ed) Candid science volume i: conversations with famous chemists. Imperial College Press, London, pp 466-475

91. Hargittai I (2003) Chapter 1, “Glenn T. Seaborg,”. In: Hargittai M (ed) Candid science volume iii: more conversations with famous chemists. Imperial College Press, London, pp 1-17

Publisher's note Springer Nature remains neutral with regard to jurisdictional claims in published maps and institutional affiliations. 